\title{
Review
}

Neuropsychobiology

Neuropsychobiology 2013;68:1-14

DOI: 10.1159/000350946
Received: September 28, 2012

Accepted after revision: March 24, 2013

Published online: June 15, 2013

\section{Neuroscience of Exercise: From Neurobiology Mechanisms to Mental Health}

\author{
Eduardo Matta Mello Portugal ${ }^{a-c}$ Thais Cevada ${ }^{a} d \quad$ Renato Sobral Monteiro-Junior ${ }^{a}$, e

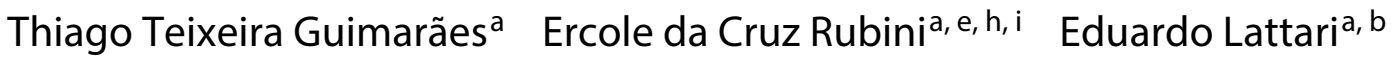 \\ Charlene Blois ${ }^{a, f, g}$ Andrea Camaz Deslandes a, b \\ ${ }^{a}$ Neuroscience Laboratory of Exercise, UGF, bxercise and Sport Sciences Graduate Program, Gama Filho University, UGF,

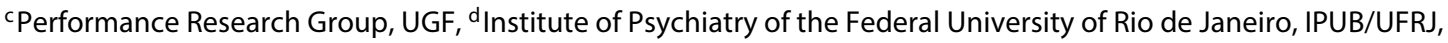

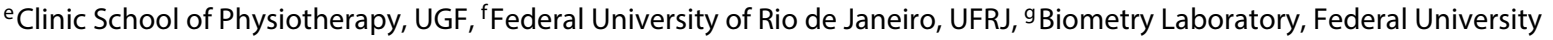 \\ of Rio de Janeiro, UFRJ, h Physical Education Course, University Estácio de Sá, and 'Laboratory of Physical Activity and Health \\ Promotion, LABSAU/UERJ, Rio de Janeiro, Brazil
}

\section{Key Words}

Neurobiology of exercise · Depression · Adherence ·

Physical training $\cdot$ Mood

\begin{abstract}
The neuroscience of exercise is a growing research area that is dedicated to furthering our understanding of the effects that exercise has on mental health and athletic performance. The present study examined three specific topics: (1) the relationship between exercise and mental disorders (e.g. major depressive disorder, dementia and Parkinson's disease), (2) the effects of exercise on the mood and mental health of athletes, and (3) the possible neurobiological mechanisms that mediate the effects of exercise. Positive responses to regular physical exercise, such as enhanced functional capacity, increased autonomy and improved self-esteem, are frequently described in the recent literature, and these responses are all good reasons for recommending regular exercise. In addition, physical exercise may improve both mood and adherence to an exercise program in healthy individuals and might modulate both the performance and
\end{abstract}

mental health of athletes. Exercise is associated with the increased synthesis and release of both neurotransmitters and neurotrophic factors, and these increases may be associated with neurogenesis, angiogenesis and neuroplasticity. This review is a call-to-action that urges researchers to consider the importance of understanding the neuroscience of physical exercise and its contributions to sports science.

Copyright ๑ 2013 S. Karger AG, Basel

Men ought to know that from nothing else but the brain come joys, delights, laughter and sports, grief, despondency, and lamentation. Hippocrates, $400 \mathrm{BC}$

\section{Introduction}

Neuroscience is a growing research area comprising a variety of multidisciplinary investigations that seek to understand the relationship between the body and the brain. At the beginning of the previous century, our knowledge of the correlation between neuroscience and exercise was

\section{KARGER}

E-Mail karger@karger.com www.karger.com/nps
(C) 2013 S. Karger AG, Basel

0302-282X/13/0681-0001\$38.00/0
Eduardo Matta Mello Portugal, MSc

Programa de Pós Graduação Stricto Sensu em Ciências do Exercício e do Esporte da Universidade Gama Filho, Rua Manoel Vitorino 553

Piedade, Rio de Janeiro, RJ 20748-900 (Brazil)

E-Mail portugalemm@yahoo.com.br 
acquired primarily through studies that investigated the effects of certain substances (e.g. ammonia) and the hemodynamic responses to them on brain function and fatigue $[1,2]$. The effects of physical exercise on the structures and functions (i.e. physiological, psychological and biochemical) of the central nervous system (CNS) have received increasing attention from the scientific community, in the context of both the potential mental health benefits for clinical populations and potential sports science applications, and these effects have been examined in studies of the exercise adherence, mental health and athlete performance [3-6]. For example, Pires [3] has shown that there is a growing number of citations for studies that investigate the central governor model and exercise.

Studies of the efficacy of using exercise to treat and/or prevent mental disorders are essential, particularly given the fast-growing elderly population and the consequent rise in the prevalence of neurodegenerative illnesses and depression. Recent increases in the incidences of several mental disorders, such as major depressive disorder (MDD) [7], dementia [8] and Parkinson's disease (PD) [9], highlight the necessity of increasing research efforts that focus on identifying treatments that can improve an individual's mental health. Although pharmacological therapy is the current gold standard for the treatment of all mental diseases, the possible adverse effects of medication contribute to failures in patient compliance. Therefore, both reducing the costs of medications and hospitalizations and enhancing the quality of life of mental health patients should be prioritized. A recent review published by members of our laboratory showed that regular exercise reduces the symptoms of MDD, dementia and PD [5]. Thus, exercise can be an adjuvant treatment for several mental diseases. One possible neurobiological mechanism underlying the positive effects of exercise is the increased synthesis and release of neurotransmitters and neurotrophins, which could result in neurogenesis, angiogenesis and neuroplasticity [10]. Nonetheless, more information regarding the neurological effects of exercise in a clinical sample is needed.

Even though there is strong evidence that exercise has positive effects on mental health and cognition, these outcomes are dependent on regular exercise practice [11]. The high rates of physical inactivity make it difficult to achieve the benefits of exercise [12]. In this context, Williams et al. [13] have found that the acute affective response to exercise is an important determinant of exercise adherence via cognitive (i.e. perceived autonomy and self-efficacy) and interoceptive (i.e. lactate accumulation and blood $\mathrm{pH}$ ) pathways. Therefore, given the modulation of adherence by the acute affective response to exer- cise, which is dependent on the exercise setting, the optimal prescription should be determined.

Although regular exercise has the potential to promote mental health, an excessive level of exercise can have adverse effects, such as overtraining [14]. In addition to exercise, other factors associated with a high level of pressure to perform well and other stressors, contribute to the high prevalence of mental disorders among elite athletes [15]. Pharmacological treatment is well accepted for the treatment of athletes [16], although other strategies, such as increased energy intake and decreased energy expenditure, are also necessary [17]. Thus, the control of psychological variables, combined with physiological variables, is essential to the success of an athlete. Corroborating this argument, Noakes [4] argues that during endurance events, structures in the CNS have an important function in determining the strategies that are used to limit exercise efforts and preserve the health of the athlete, and these structures play a role in the modulation of other body systems during exercise, ultimately contributing to improved performance.

Considering the importance of knowledge about the relationship between exercise and the broad context of neuroscience involved in mental health, along with adherence to exercise programs, performance and the diversity of the variables analyzed in these studies, we conducted a comprehensive review to identify the current state of the art in the field of the neuroscience of exercise. Thus, the effects of exercise on physiological, psychological and biochemical variables related to CNS structure and function were analyzed. Our study began by examining the relationships between exercise and the most prevalent mood disorders and neurodegenerative diseases. However, it is also worth discussing the acute effects that exercise has on mood and adherence to an exercise program. Moreover, what protects the mind does not always protect the body; diagnoses of various mental disorders are surprisingly common among athletes who have been subjected to overtraining, fatigue, competition-related stress, injuries, failure and retirement. Thus, the brain may contribute to diminished performance or increased fatigue in some circumstances. The final section of this article examines a neurobiological hypothesis that may explain the mechanisms that underlie the effects of exercise on mental health.

\section{Mental Disorders and Neurodegenerative Disorders}

\section{Major Depressive Disorder}

Data from the World Health Organization [18] provide evidence of a causal relationship between MDD and the 
subsequent development of a disability, and some diseases that have MDD as a comorbidity are associated with a diminished Mean Health Score [18]. There is a relationship among morbidity due to this disease, aging, the number of systemic illnesses and a lack of physical exercise [7].

Several hypotheses regarding the mechanisms that underlie the pathophysiology of MDD have been studied. The most popular theory involves the activity of monoamines, namely reductions in the activities of serotonin and norepinephrine [19]. Another mechanism involved in depression is the hyperactivity of the hypothalamicpituitary-adrenal axis due to the increased release of cortisol and corticotropin-releasing factor [20].

The effect of exercise, as an adjunct to pharmacological treatment, on depressive symptoms has been studied $[5,21]$. Follow-up studies, clinical trials and randomized controlled trials have found evidence of a positive correlation between regular physical exercise and a reduction in depressive symptoms [21-25]. Both strength training and aerobic training have positive effects in the treatment of depression [25]. Furthermore, high-intensity strength training ( $80 \%$ of one maximum workload lifted (1 repetition maximum (RM)) [23], moderate aerobic training $(17 \mathrm{kcal} / \mathrm{kg} / \mathrm{min})$ [22] and supervised moderate-intensity training (70-80\% HRR) [21] were all shown to induce positive responses in an investigation of the effect of exercise on depressive symptoms. In contrast, Krogh et al. [26] have observed the opposite pattern of results in a recent meta-analysis. They concluded that exercise has small short-term effects on the severity of depressive symptoms but that the existing data regarding the longterm effects of exercise are inconclusive. The lack of inclusion criteria, even for studies of good quality, can explain these results. Using rigorous inclusion criteria, our group performed a meta-analysis [25] that showed that both aerobic exercise and strength training have positive effects on depressive symptoms. These effects are substantial in elderly individuals and individuals who have mild depressive symptoms [25].

It appears that the efficacy of using exercise to reduce the severity of depressive symptoms depends on the level of adherence to an optimal exercise regimen; a combination of moderate-intensity aerobic training and high-intensity strength training may provide more positive benefits than other exercise programs. Neurobiological mechanisms can explain these positive effects (see the Neurobiology of Exercise section). However, there are both methodological limitations (i.e. lack of statistically significant results, poor sample selection criterion and MDD diagnostics, no adequate control of exercise regimen) that limit our understanding of this observation. In summary, more research is necessary to better understand the effects of exercise on the depressive symptoms of MDD patients.

\section{Dementia}

Dementia is the most prevalent neurodegenerative disease worldwide. In a review study it was estimated that 24.3 million cases have been reported, and 4.6 million new cases are reported annually in the world [27]. Despite the heterogeneity of its symptoms, dementia is associated with the progressive loss of various cognitive functions and the consequent impairment of an individual's ability to perform daily life activities. Mental stimulation, proper nutrition and exercise appear to exert both prophylactic and therapeutic effects on the development and progression of neurodegenerative dementia [28-30]. Physical activity alone is associated with a $28 \%$ reduction in an individual's risk of developing the disease [31].

Given the possible adverse effects related to pharmacological treatment, the quality of life and the general well-being of individuals who suffer from dementia can be compromised [32]. Thus, it is important to investigate alternative, non-pharmacological treatment strategies such as exercise [33]. A meta-analysis conducted by Hein et al. [32] found that regular exercise performed with the mean training duration from all studies of 23 weeks, with a range of 2-112 weeks, had positive effects on both cognitive and behavioral improvement. There was an average of 3.6 sessions per week, ranging from 1 to 6 sessions, with each session lasting an average of 45 min (mean) and ranging from 20 to $150 \mathrm{~min}$. However, Forbes et al. [34] conclude that there is not sufficient evidence to determine whether participation in a regular exercise program actually benefits people with dementia. The inconclusive results of their study may have been obtained because these authors chose criteria for assessing the methodological quality of existing studies that resulted in the inclusion of only two studies in their meta-analysis.

There is some evidence that exercise can improve cognitive function, the ability to perform daily life activities and the ability to walk in dementia patients, but both the low intensities of the prescribed exercise regimens that were used in the studies that Forbes et al. [34] reviewed and the methodological qualities of those studies can be criticized. For example, a recent study examined 62 dementia patients who underwent 3 months of progressive resistance and functional group training. The resistance training targeted functionally relevant muscle groups at a submaximal intensity (70-80\% of $1 \mathrm{RM})$ and was performed in groups of 4-6 participants for 3 months ( $2 \mathrm{~h}$, twice a week). 
This study found evidence of increases in both the strength and functional capacities of the treated patients that were not observed among the patients in the control group [35].

Alzheimer's disease (AD) is the most prevalent form of dementia and is associated with the accumulation of senile plaques and neurofibrillary tangles that result in the atrophy of the hippocampus. Data from animal models suggest that in the animal strains that have been studied, physical exercise is associated with a reduction in the formation of $\beta$-amyloid deposits and the enhanced clearance of these deposits. $\beta$-Amyloid is a principal component of the senile plaques that accumulate in the brains of $\mathrm{AD}$ patients, and exercise has also been shown to ameliorate the accumulation of the phosphorylated form of the $\tau$ protein, which is essential for the formation of neurofibrillary tangles. In addition, physical activity appears to promote mechanisms of neuronal resilience that reduce inflammation in the CNS [36].

Previous studies have shown that regular participation in a physical activity, such as strength training, aerobics or walking, strength, flexibility, balance and aerobic training, or a combination of these exercises for 16 weeks or 1 year is able to improve some parameters related to health [5]. The quality of life in AD patients can be improved by increasing their strength and balance, thus reducing their risk of falling and increasing the facility with which they are able to perform daily life activities [5].

Because of the importance that exercise appears to have in improving the lives of $\mathrm{AD}$ patients, randomized controlled trials that investigate the effects of exercise on the synthesis and release of neurotrophic factors, neurotransmitters, hormones and other physiological markers are still needed, as are studies that use more precise methods of measuring these effects.

\section{Parkinson's Disease}

$\mathrm{PD}$ is the second most prevalent neurodegenerative disease among elderly individuals, and it generally affects men more often than it affects women [37]. The disease is characterized by the loss of dopaminergic neurons in the substantia nigra, and it is associated with diminished mitochondrial activity that results in an increased production of reactive oxygen species (ROS) [38]. The cardinal symptoms of PD are hypokinesia, tremors, postural imbalances and gait deficits. Pathological signs are most common among individuals who are between the ages of 50 and 60 [39], but symptoms may appear during a number of stages of life. In addition to the aforementioned motor impairments, behavioral, cognitive and other functional changes can be observed at different stages of PD. Although drug treatment is the most widely used method of treating PD, recent studies have shown that exercise and pharmacological therapy are important interventions to improve motor control, autonomy and awareness of the patient's day-today quality of life [40]. In addition, individuals who have higher fitness levels have a $33 \%$ lower risk $(R R=0.67)$ of developing PD [41]. Participating in an exercise program that involves activities with moderate-to-vigorous intensity during middle age appears to have a neuroprotective effect of as high as $38 \%(R R=0.62)$ for individuals who are not affected by the disease [41]. Given the relatively low cost of engaging an individual in a physical training program and the various benefits that can be achieved by doing so, exercise should be given special attention as a possible means of protecting against or reducing the effects of this disease.

The evidence for the effectiveness of exercise in ameliorating the symptoms of PD has been favorable, but it remains limited in scope. Both aerobic exercise (between 40 and $60 \%$ HRres, 3-4 times per week, 30 min per session) and strength training (2-3 times per week, $40-80 \%$ of $1 \mathrm{RM}$ ) appear to result in improved motor function in PD patients [42]; these types of exercise also appear to improve the quality of life in individuals with $\operatorname{PD}[43,44]$. However, strength training appears to be of greater benefit to patients with the disease. Bloomer et al. [45] have assessed the impact of an exercise program on the activities of some oxidative factors $\left(\mathrm{C}_{3} \mathrm{H}_{4} \mathrm{O}_{2}\right.$ and $\left.\mathrm{H}_{2} \mathrm{O}_{2}\right)$. Individuals engaged in resistance training twice per week for a period of 8 weeks ( 3 sets, $5-8$ reps, until momentary muscular failure). Although these authors did not identify any significant between-group differences in the activities of the antioxidant enzymes that were analyzed, the group that had engaged in resistance training showed significant (15-16\%) reductions in the serum levels of various biomarkers of oxidative stress, whereas members of the control group showed 14\% increases in the serum levels of these markers. Importantly, this reduction occurred after a relatively short period of training (8 weeks) with a low frequency (twice per week).

This result suggests that the positive physiological effects of strength training are rapid and indicates that there may be an optimal dose-response relationship. Moreover, PD patients who participated in exercise programs that included both high-intensity strength training (60-80\% $4 \mathrm{RM}$ ) and balance training showed improved abilities to control the stability of their bodies and were able to maintain the same level of performance over a period of 1 month after the conclusion of their training program [46]. These findings support the hypothesis that the effects of this type of training program remain stable even after a 
period during which a PD patient does not participate in regular training. These improvements may be related to neurobiological changes that occur as a result of physical exercise, particularly neurogenesis [47], an increase in mitochondrial activity and an increase in the synthesis of certain neurotransmitters, such as dopamine [48]. The neurobiological mechanisms of the effects of exercise are discussed in detail in the Neurobiology of Exercise section.

Currently, there are several practical considerations that must be considered when determining the appropriate exercise regimen for $\mathrm{PD}$ patients. Data from the recent literature recommend aerobic activities using a cycle ergometer and body support that are performed 3-5 times per week at a level of intensity (low, moderate or high) determined on the basis of the trainability and disease stage of each patient. The levels of intensity are characterized as follows: an intensity $<40 \%$ of the heart rate reserve (HRR) or $\mathrm{VO}_{2}$ reserve $\left(\mathrm{VO}_{2} \mathrm{R}\right)$ is considered low; an intensity $<60 \%$ of the HRR or $\mathrm{VO}_{2} \mathrm{R}$ is considered moderate, and an intensity $>60 \% \mathrm{HRR}$ or $\mathrm{VO}_{2} \mathrm{R}$ is considered high. The recommendations for strength training for $\mathrm{PD}$ patients prioritize strengthening the lower limbs and suggest strength training 2-3 times per week at an intensity of $40-50 \% 1 \mathrm{RM}$ (light) or $60-80 \% 1 \mathrm{RM}$ (moderate/high) depending on the aforementioned conditions regarding the disease stage and trainability of each patient. The literature also suggests that both aerobic and strength training should be accompanied by functional exercises, especially exercises involving gait (fig. 1) [49].

\section{Mood and Anxiety: Acute Effects of Exercise, Adherence to an Exercise Program, and Athletic Performance}

\section{Effects of Aerobic Exercise}

There are many scientific studies that provide evidence of the beneficial effects of exercise on disease prevention and overall health. However, promoting adherence to programs of regular physical activity is one of the greatest challenges in the field of sports science. The affective response that a single exercise session provokes has been shown to predict the level of engagement of a participant over the course of the subsequent 6-12 months [13]. The link between affective responses and adherence has been explained by Williams using an integrative model [for a review, see 6]. Thus, it is likely that improving our understanding of the effects that different types of exercise have on human behavior may also improve our ability to increase the rates of adherence to exercise programs.
According to Ekkekakis and Petruzzello [50], there may be a U-shaped relationship between aerobic exercise intensity and affective state. This theory suggests that the optimal intensity, the one that produces the most positive affective response, would be a moderate intensity that is near the ventilatory threshold $\left(\sim 65 \% \mathrm{VO}_{2 \max }\right.$ [51]). It may be that intensities above the ventilatory threshold are perceived as threatening by most individuals and, therefore, tend to generate a negative affective state [52]. Moreover, although intensities below the ventilatory threshold have a high individual variability, these lower intensities are perceived as pleasurable by most individuals $[52,53]$. A meta-analysis conducted by Reed and Ones [54] showed that low-intensity exercises that had a duration of $35 \mathrm{~min}$ or less also induced a strong activation of positive affect. In contrast, recent research has shown that an exercise protocol that included intervals of high-intensity generated more pleasure than a program that used a continuous moderate intensity [55]. There is also evidence that suggests that positive behavioral outcomes tend to occur after exercising at a self-selected intensity [56].

It appears that moderate-intensity exercise programs result in improved behavioral, affective, mood or anxiety responses [53]. The response to this type of exercise regimen represents a common point between two classical models of exercise efficacy that have been proposed in the literature (the inverted U-shaped curve and circumplex models of affect), both of which are presented in figure 2 . The circumplex model consists of a two-dimensional structure in which combinations of arousal and affective valence are represented in quadrants [for a review, see 57].

The substantial variation in the findings of studies of exercise efficacy may be attributed to the use of different methods of measuring behavior and to the failure to standardize the pretest scores in addition to the effects that depend on an individual's level of physical fitness. For example, affective state, mood and anxiety are often treated as synonyms, but there are differences in the operational definitions of these terms that could theoretically result in differing interpretations when comparing the results. Thus, it appears that the variable that is termed adherence to an exercise program is the most consistently applied measure of affective state in this context [13].

\section{Effects of Strength Training}

Despite the increasing interest in the acute effects of exercise on affect, mood and anxiety, few studies have attempted to investigate the differential influences of various types of exercise. For example, the effects of strength 


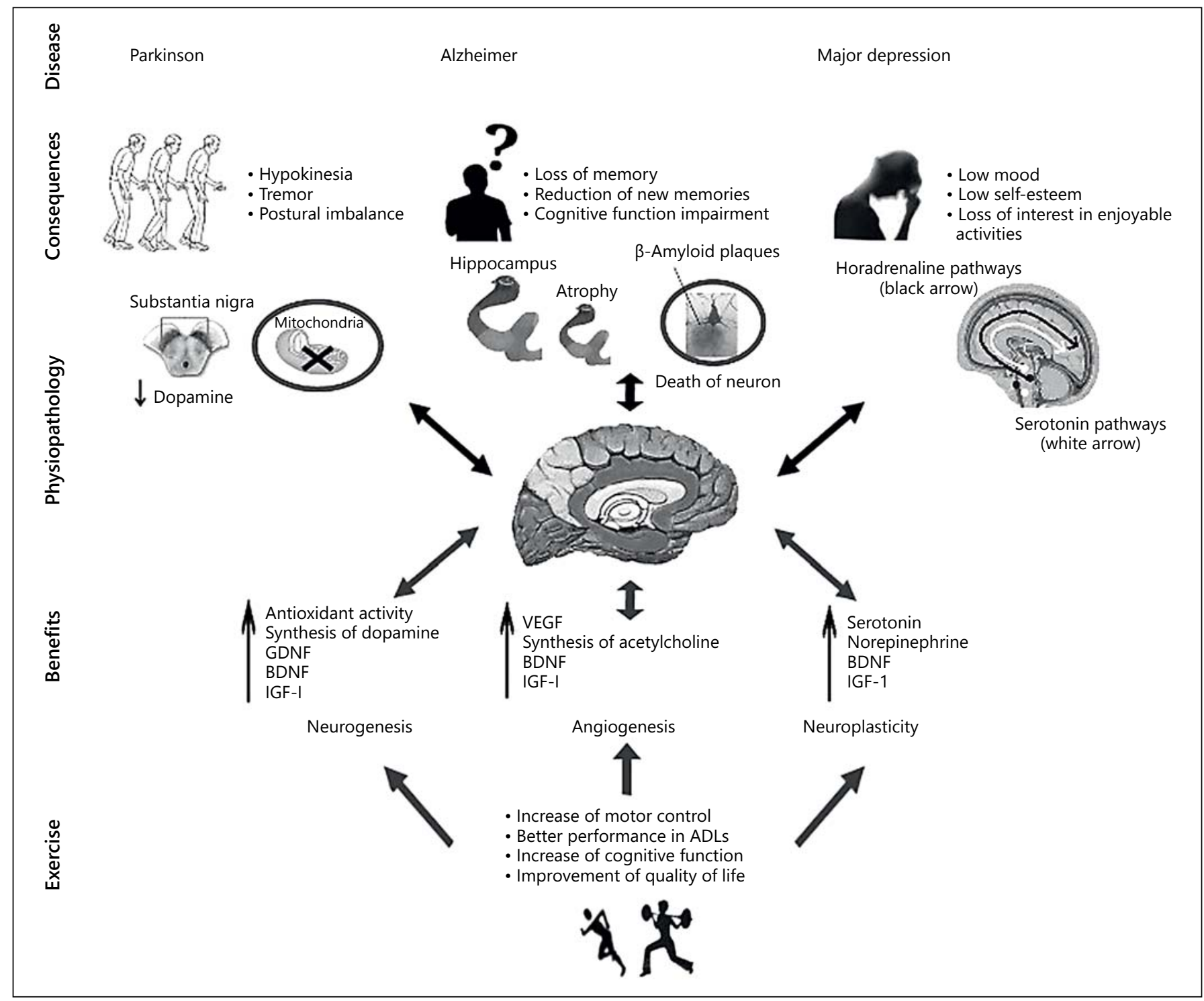

Fig. 1. Effects of exercise on neurodegenerative diseases and mental disorders. The reductions in dopamine and mitochondrial function, the generation of $\beta$-amyloid plaques and hippocampal atrophy and the decreases in the serotonin and noradrenaline levels (in the hippocampus, hypothalamus, amygdala, cortex and other parts of brain) are the primary alterations that result in $\mathrm{PD}, \mathrm{AD}$ and MDD, respectively. Exercise training could be beneficial because neurotransmitters and neurotrophic factors are synthesized in response to physical exertion. These factors could delay of the progression of neurodegenerative diseases and mental disorders. Moreover, exercise improves physical function and functional autonomy. ADLs = Activities of daily living. training are rarely compared with the effects of aerobic exercise [58].

The results of studies of the acute effects of strength training on mood have been contradictory, and studies that have focused on low- and high-intensity strength training programs have had divergent results [58]. Furthermore, the time between the conclusion of an exercise session and the time at which the mental state of the par- ticipant is evaluated appears to influence the observations that are obtained. It appears that a minimum recovery time of $20 \mathrm{~min}$ must elapse before a decrease in the anxiety level of a participant can be observed, and participants require a 40-min recovery period before a reduction in their levels of physical exertion can be discerned $[59,60]$. When different types of physical exercise are compared, both strength training and aerobic exer- 


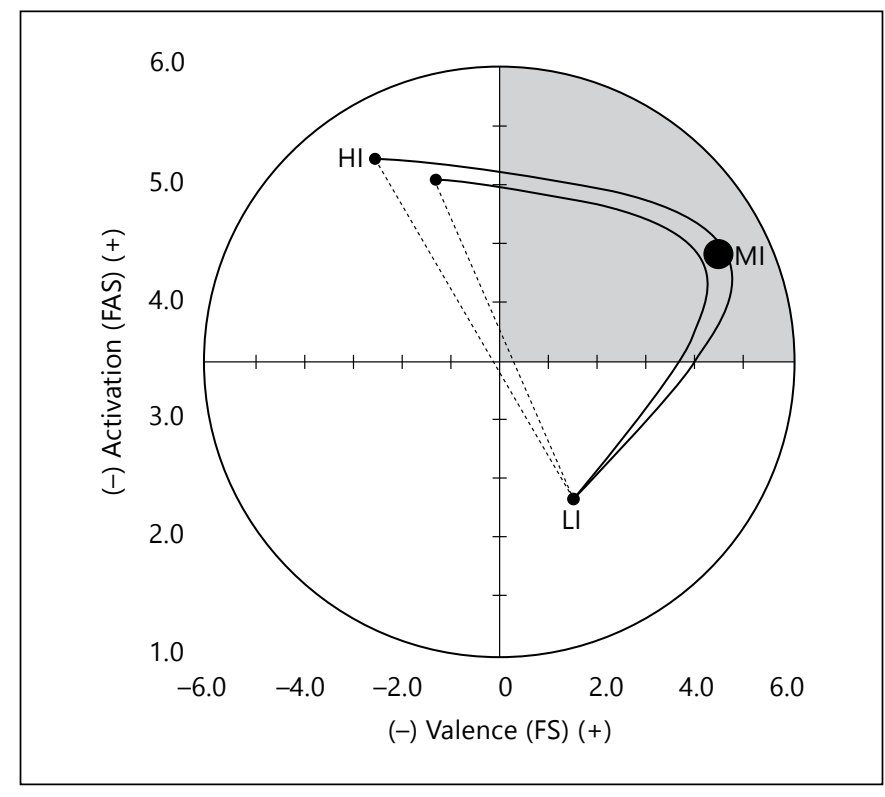

Fig. 2. Kinetics of the affective response to exercise in the circumplex model: Two theories (inverted-U and inverted-J) suggest the same optimal point (MI). The lines represent the inverted-U and inverted-J forms, which are modulated by the light intensity (LI), moderate intensity (MI), and high intensity (HI) of the exercise. The gray area represents the positive affect activation that could promote well-being and adherence to an exercise program.

cise appear to promote poorer moods among participants who are surveyed immediately after an exercise session; however, there is a tendency for improvement in the moods of the participants after 30 min of recovery [61]. The recovery interval between the sets within a strength training session may be another variable that influences the mood responses of participants. A long recovery interval ( 3 min between two sets of exercises) may result in an increased positive affect, whereas a short interval ( $1 \mathrm{~min}$ ) could instead result in increased anxiety [60]. Interestingly, Bellezza et al. [62] showed that positive affective responses in women were more likely to occur when small muscle groups were exercised at the beginning of an exercise session.

Thus, it appears that there is no consensus regarding which of the aforementioned acute variables that can be incorporated into a strength-training program has the most profound impact on mood.

\section{Brain and Sports}

In general, the literature shows that physical exercise has favorable effects on mental health. Surprisingly, populations that are composed of athletes may be subject to specific exercise-related physical and mental stresses that favor the emergence of mood and anxiety disorders [16]. Although sports psychiatry has been poorly studied to date, investigations in this field should be emphasized because exercise-induced changes in an athlete's behavior and mental health may affect his/her performance in both individual and team sports [63]. In conjunction with these considerations, studies of the neuroscience of exercise and sports aim to investigate the effects of central changes (neurophysiological and psychological) on athletic performance and mental health $[64,65]$.

The mental health of an athlete is related to his/her ability to control emotions, manage stress and cope with injuries, the excesses training and competitions. Top athletes constantly experience stress and emotional overload because success is always associated with results and achievements. The physical and emotional stresses cause athletes to constantly live on the edge psychologically. Consequently, symptoms such as low motivation, sadness, depressed mood, anger, decreased self-esteem, loss of identity, loss of self-confidence and even depression and suicidal ideation become common in this population $[15,16]$. Unfortunately, the prevalence of certain behaviors or mental states (e.g. high levels of anxiety, attention deficit, hyperactivity and suicidal thoughts) that are risk factors for mental illness (including overtraining syndrome, psychosis, bipolar disorders and anxiety) are rarely studied.

In addition, a complex pattern of neurophysiological factors (mood, pain tolerance and previous experiences), neurobiological changes (cerebral metabolic changes, substrate depletion, alterations in regional neurotransmitter levels and cerebral temperature), central command activation (sense of effort) and peripheral factors (afferents signals and the cardiopulmonary system) may compromise the performance of an athlete by inducing fatigue signals. Fatigue is characterized by an inability to continue to execute a particular task, and the onset or severity of fatigue may depend on the type, intensity and/or duration of a particular task [66]. Fatigue may be considered an increased difficulty in maintaining a given exercise intensity and can be assessed with ratings of perceived exertion (RPE), for example by the Borg scale [67]. A recent study investigated interventions related to temperature and cerebral oxygenation, and these variables are suggested to be trigger points and important determinants for the development of central fatigue [68-71]. The temperature of the brain is determined by the balance between the heat produced by cerebral energy turnover and the heat that is removed, primarily by cerebral blood flow $(\mathrm{CBF})$. The level of convection of heat between tissue and 
capillaries is considered to be very high [72]. The global $\mathrm{CBF}$ is influenced by the partial pressure of $\mathrm{CO}_{2}$ in the blood $\left(\mathrm{PaCO}_{2}\right)$. During low- and moderate-intensity exercise, the $\mathrm{PaCO}_{2}$ and $\mathrm{CBF}$ remain unchanged from the level at rest $(50-55 \mathrm{ml} / 100 \mathrm{~g} / \mathrm{mm})$, and during high-intensity exercise, hyperventilation occurs and the $\mathrm{PaCO}_{2}$ decreases, resulting in vasoconstriction of the cerebral arterioles and a consequent decrease in CBF [66]. During prolonged exercise, hyperthermia causes the global CBF to decrease by $20 \%$ [68]. The preservation of the autoregulatory activity of the brain depends on the ability to increase and maintain sufficient cardiac output because reduced blood pressure and cardiac output induce peripheral and brain vasoconstriction [73].

Under normal conditions, the decrease in $\mathrm{PaCO}_{2}$ due to high-intensity exercise does not restrict the supply of oxygen to the brain; this mechanism is offset by the poor perfusion of oxygen. However, when exercise is performed in extreme conditions, such as at high altitude, under conditions of dehydration or at high temperatures, the oxygen supply decreases and there is no restriction of cerebral metabolism, consequently leading to neurological deficits [74]. Thus, the occurrence of hyperthermiainduced fatigue is supported by the observation that exercise in hot conditions reduces the voluntary activation of motor neurons during a sustained maximal muscle contraction [75]. The reduced work capacity may be related to more than one factor, but exhaustion during prolonged exercise in the heat seems to coincide with the attainment of a critical internal temperature [76, 77]. However, there is evidence contradicting this mechanism. Girard et al. [78] investigated the effect of hot conditions on repeated sprint cycling performance and did not observe any effect on the pattern or extent of isometric knee extensor fatigue following repeated cycling sprints in the absence of hyperthermia.

In general, the neurobiological changes that are related to fatigue include metabolic changes in the brain, particularly changes in the levels of serotonin, dopamine and norepinephrine. For example, high levels of serotonin are associated with negative behaviors, lethargy and sleepiness [79]. One possible mechanism for these effects described in the literature is competition between tryptophan and free fatty acids for binding sites on the albumin protein [79]. Both physical and mental exhaustion may be related to dopamine deficiencies in specific brain areas such as the ventral tegmental area of the midbrain, the substantial nigra pars compacta and the infundibular nucleus of the hypothalamus. Dopamine deficiencies in these brain areas in conjunction with exhaustion support the hypothesis that low levels of dopamine could reduce motivation and motor coordination and could lead to lethargy and fatigue [71]. Norepinephrine is related to a heightened state of arousal (e.g. alertness) and activation of the adrenal medulla, which stimulates cardiovascular responses, blood perfusion and energy supply [80]. A recent study found that compounds with central action, such as dopamine, norepinephrine and glucose, best predict the rate of increase in the RPE during constant exercise sets at different intensities [81]. The RPE seems to be additionally influenced by brain activity and cognitive processes such as emotion, motivation and memory [82]. Therefore, in exercises with a constant load, the RPE becomes a good tool for predicting the remaining time until fatigue. The linear increase in the RPE observed in the study of Pires et al. [81] was independent of the intensity of the exercise. One possible mechanism could be the progressive and continuous accumulation of metabolites in the periphery [83]. The metabolic variables $(\mathrm{pH}$ and the lactate, catecholamine, glucose and potassium concentrations) were responsible for a greater variation in the slope of the RPE in both moderate intensity exercise and high-intensity exercise [81]. This same study also showed that metabolic variables combined with cardiopulmonary variables (heart rate and breathing) may satisfactorily predict the time to exhaustion for both moderate- and high-intensity exercise. Therefore, based on these results, it becomes possible to assume that the high level of cerebral blood glucose coupled with the availability of dopamine as the exercise progressed could have led to an increase in brain activity, which may in turn have influenced RPE [81].

During prolonged exercise or when an individual is operating with depleted energy reserves, the catabolism of amino acids occurs, and the production/removal of ammonia becomes another fatigue-related concern. The accumulation of ammonium ions in astrocytes may cause neurotoxicity and impaired cerebral circulation. The presence of ammonia also affects the levels of various neurotransmitters (glutamate, glutamine and GABA), and it encourages the release of factors associated with infection (primarily interleukins such as IL-6) [84] that are also related to mood and fatigue. A considerable decrease in the ratio of the cerebral rates of oxygen and carbohydrate metabolism may occur during vigorous exercise, and the diminished supply of oxygen could cause a major disruption in cerebral metabolism that results in hyperventilation and hypocapnia [85].

Another condition that occurs in some athletes is overtraining. Overtraining appears to be a maladaptive response to excessive exercise without adequate rest, result- 
ing in perturbations to multiple body systems (neurological, endocrine and immune systems) coupled with mood changes [86]. The symptoms of overtraining include depressed mood, general apathy, decreased self-esteem, emotional instability, impaired performance, restlessness, irritability, disturbed sleep, weight loss, loss of appetite, increased resting heart rate, increased vulnerability to injuries, hormonal changes and a lack of supercompensation [87]. Armstrong and VanHeest [14] showed that $60 \%$ of long-distance runners experienced symptoms of overtraining at some point during their careers, $50 \%$ of professional soccer players experienced these symptoms during a single competitive season (5 months), and 33\% of basketball players experienced these symptoms during their 6-week training period. For most athletes, the relationship between psychological stress, anxiety and athletic performance is best understood via a self-regulation model that consists in training regulation by emotional status [88].

In sports, factors such as concentration, emotional control and coping strategies are linked to better performance $[63,88]$. The relationship between psychological stress, anxiety and performance in sports is better demonstrated by the individual zones of optimal functioning (IZOF) as proposed by Hanin [89], providing a functional explanation for the dynamics of the emotion-performance relationship based on a detailed description of athletes' idiosyncratic subjective experiences [90]. In addition, the model suggests that self-emotional regulation by athletes is an important tool during competitions [88]. Another physiological mechanism widely discussed is the central governor model (CGM) proposed by Noakes et al. [91]. The CGM shows that all types of exercise are regulated by the CNS. The CNS is subconsciously capable of managing neuromuscular recruitment and calculating the metabolic cost to execute a task and succeed. Therefore, the CNS's anticipatory control should prevent the catastrophic failure of the human body [91]. The implementation of a new approach to exercise science, after this paradigm shift between peripheral control and central control proposed by Noakes [92], is highly criticized [93-95]. However, according to Pires [3], the science community has almost accepted this theory. This author suggests that these old concepts have new interpretations and that other aspects, such as the number of citations and the increasing debate related to CGM, should be considered evidence of the acceptance of this new theory in exercise science. From these new ideas arise the crises that promote scientific revolutions, and the exercise science follows a pattern similar to the kuhnian model of scientific discovery [3].
In summary, the need for a comprehensive and integrated multidisciplinary approach to understanding the effects of central changes on athletic performance and the mental health of athletes is evident from the results presented in the existing literature.

\section{Neurobiology of Exercise}

\section{Acute Exercise Mechanisms}

There is evidence that physical exercise promotes changes in the human brain due to increases in metabolism, oxygenation and blood flow in the brain. Unfortunately, our knowledge of how the human brain is affected by physical exercise interventions is limited, and the available evidence is predominantly from animal studies $[5,10]$. Studies with animals have shown that physical exercise modulates the major CNS neurotransmitters that are associated with an individual's state of alertness (norepinephrine), the pleasure and reward system (dopamine) and the level of anxiety (serotonin). Moreover, changes in the levels of these neurotransmitters may have different consequences depending on the type(s) of receptors and the cortical areas that are activated [96]. Other neurochemical factors that may be released during physical activities include opioids and endocannabinoids, which promote a sense of euphoria and well-being, anxiolytic effects, sedation and decreased sensitivity to pain in humans [97].

Other neuromodulators that are activated by acute exercise are trophic factors. Studies in animals have shown that the expression levels of brain-derived neurotrophic factor (BDNF), insulin-like growth factor (IGF-1), vascular endothelial growth factor (VEGF), neurotrophin-3 (NT3), fibroblast growth factor (FGF-2), glial cell linederived neurotrophic factor (GDNF), epidermal growth factor (EGF) and nerve growth factor (NGF) appear to increase in conjunction with exercise interventions, and these trophic factors act as survival, proliferation and maturation factors in specific cells in the brain [98]. Upon binding to their specific receptors, these factors can promote the activation of signaling pathways by activating the Ras/Raf proteins, P13K (protein 13 kinase)/Akt (protein kinase $B$ ) and cAMP response element-binding (CREB) protein, which is a protein that is associated with transcription. The aforementioned neurotrophic factors can even inhibit signals in the caspase-mediated apoptotic pathway. In the CNS, these trophic factors can both act as modulators and be modulated by neurotransmitters, which may play a substantial role in determining an individual's level of cognition and behaviors. Sex hor- 
mones may be associated with the regulation and function of trophic factors [99].

In humans, atrial natriuretic peptide (ANP) has a function in controlling the body's water volume. ANP is primarily involved in pathways that affect the hormones of the renin-angiotensin system. Thus, ANP has been shown to play an important role in regulating catecholamines and gonadal hormones in addition to modulating the mood and behavioral functions that are mediated by its association with vasopressin [100].

\section{Chronic Exercise Mechanisms}

The long-term effects of chronic participation in physical exercise appear to result in different responses and adaptations than those that can be observed following acute exercise participation (after only one session). Increases in $\mathrm{CBF}$, the expression of a number of trophic factors (BDNF, IGF-1, VEGF, NT3, FGF-2, GDNF, EGF and NGF) and the induction of pro-inflammatory processes promote neurogenesis, angiogenesis and synaptogenesis [98]. Moreover, other factors, such as increased metabolism, cognitive stimulation, antidepressant use, dietary restriction, social contact and environmental enrichment, also promote cell proliferation [101]. However, aging, stress, neurodegenerative diseases and the accumulation of free radicals tend to inhibit neurogenesis [98]. Interestingly, van Praag [102] postulated that adhering to a diet that is rich in antioxidants and anti-inflammatory compounds in combination with voluntary exercise participation would have significantly better results than either diet or exercise alone. Moreover, cognitive stimulation, elevated VEGF levels, caloric restriction and accelerated metabolism might contribute to enhanced angiogenesis [102]. It is expected that the results found in these animal studies will also be found in humans because the underlying mechanisms exhibit similar responses in animals and humans [103].

The activation of the hypothalamus-pituitary-adrenal (HPA) axis, the stress axis, also changes in accordance with the type, duration and intensity of physical exercise that an individual performs. When stimulated, the hypothalamus releases corticotrophin-releasing hormone (CRH). The release of CRH then stimulates the pituitary gland and results in the release of adrenocorticotropic hormone, which interacts with the adrenal gland and causes it to secrete the stress hormone cortisol in humans or corticosterone in animals [104]. Although physical exercise is an acute stressor, chronic exercise can have neuroprotective effects instead. These effects are illustrated by the finding that subjects who had undergone phys- ical training had lower levels of cortisol both at rest and in response to a stressor than sedentary subjects [105]. Some of the hypotheses presented in the literature that address the correlation between the HPA axis and exercise suggest that biological changes in the activity of the HPA axis, such as those associated with an enhanced density and efficiency of mineralocorticoid receptors, lower cortisol levels and the inhibition of cortisol synthesis, could be an efficient negative feedback mechanism [104]. In addition, an increased vasopressin/CRH ratio might have positive effects on this negative feedback for chronic stress through a reduction in pituitary stimulation [106]. Moreover, the effect of decreased CRH mRNA transcription in the paraventricular nucleus of the hypothalamus could result in diminished activity in the anterior pituitary. These changes may be associated with an improved immune response [107].

Interestingly, in addition to human studies, animal studies have shown that hormonal alterations can influence both behavior and alimentary functions by interacting with anorexigenic factors, such as glucose and leptin, and orexigenic factors, such as neuropeptide $\mathrm{Y}$ and ghrelin. These factors may regulate the food circuitry in the ventrolateral hypothalamus. This system could be activated during stressful situations, and a combination of amino acid intake and the activation of the HPA axis could cause the body to store energy for use when coping with a stressful situation [108].

Antioxidant effects have also been observed in individuals who have participated in aerobic exercise for an extended period of time [109]. These effects could be explained by ROS-mediated signaling; the mitochondrial production of ROS that results from a high metabolic demand may induce signaling mediated by nuclear factor$\kappa \mathrm{B}$. Nuclear factor $-\kappa \mathrm{B}$ then induces the expression of genes that encode antioxidant enzymes that combat the accumulation of free radicals, such as superoxide dismutase, catalase and glutathione peroxidase [110]. Furthermore, the increase in the concentration of ROS primarily modulates the activity of intracellular pathways that are involved in the behavior of exercise muscle fibers. Consistent with this hypothesis, animal studies have shown that an elevated concentration of ROS might activate the CREB protein and the peroxisome proliferatoractivated receptor- $\gamma$ coactivator (PGC- $1 \alpha$ ) in the nucleus, thereby inducing mitochondrial biogenesis. Thus, chronic aerobic exercise may have both antioxidant-mediated and mitochondrial biogenic activity [110].

Chronic exercise can even result in changes in genetic structures, such as those of the telomeres in leukocytes. 


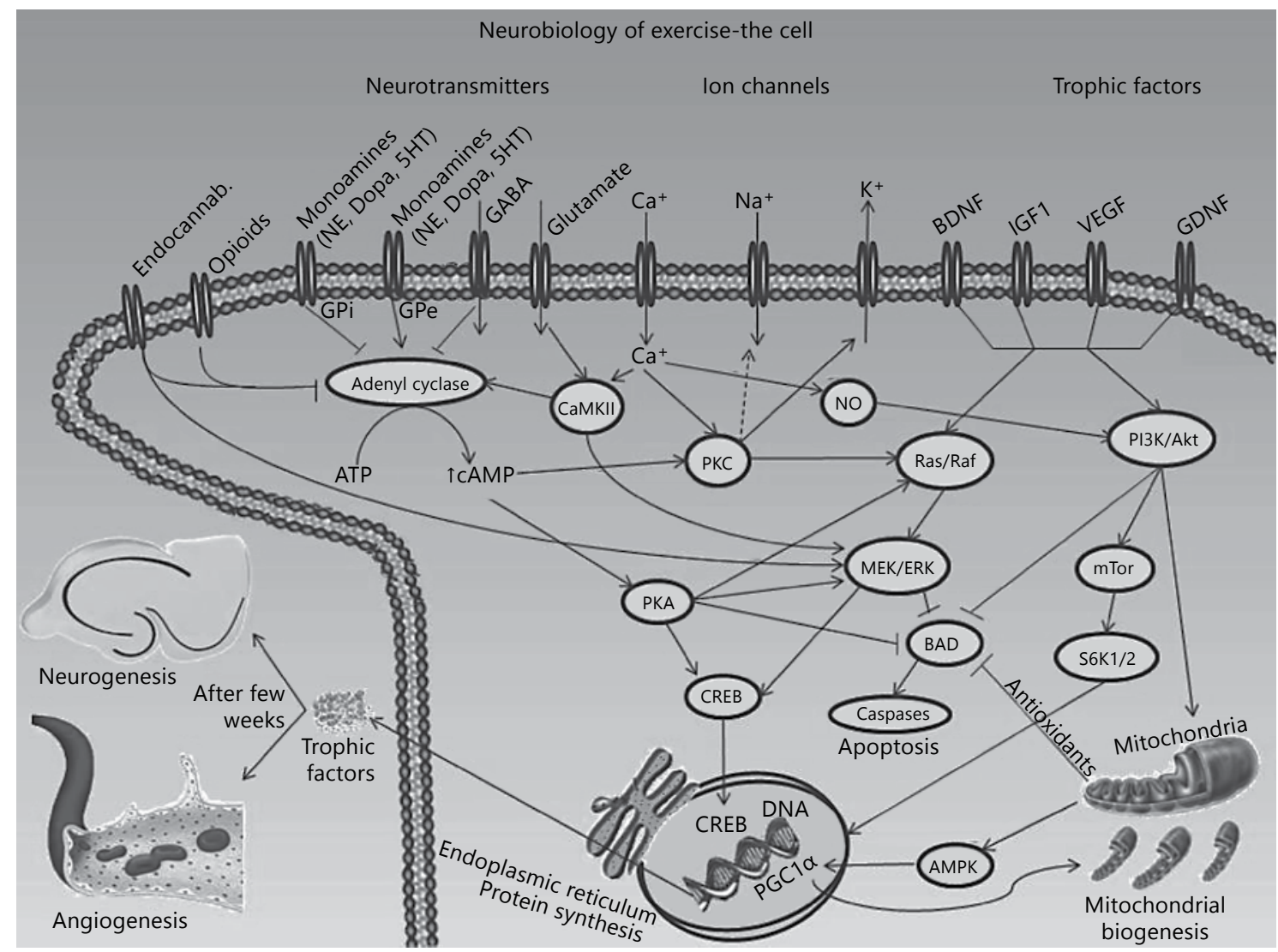

Fig. 3. Neurobiology of exercise $=$ Endocannab $=$ endocannabinoids; $\mathrm{NE}=$ norepinephrine; Dopa $=$ dopamine; $5 \mathrm{HT}=$ serotonin; $\mathrm{Ca}^{+}$= calcium ion; $\mathrm{Na}^{+}=$sodium ion; $\mathrm{K}^{+}=$potassium ion; $\mathrm{GPi}=$ $\mathrm{G}$ protein inhibitors; $\mathrm{GPe}=\mathrm{G}$ protein excitors; Adenyl Cyclase $=$ adenylate cyclase; $\mathrm{CaMKII}=$ calcium calmodulin-dependent protein kinase II; ATP = adenosine triphosphate; cAMP = cyclic ad-

Individuals who practice moderate physical activity appear to havelonger telomeres than sedentaryindividuals and those who practice exercise that is either higher or lower in intensity. The reported results regarding whether physical exercise enhances telomerase activity are still inconclusive [111].

\section{Chronic Diseases}

For individuals with depression, several biochemical, physiological and neurophysiological analyses of exercise-related effects on the brain have shown positive effects with regard to the alleviation of depressive symptoms. Moreover, the exercise-induced release of neurotransmitters and the elevation in neurotrophin activity contribute to both neuroplasticity [5] and normal (unsuppressed) cortical activity [24] and may play a role in enosine monophosphate; $\mathrm{PKC}=$ protein kinase $\mathrm{C} ; \mathrm{PKA}=$ protein kinase $\mathrm{A} ; \mathrm{NO}=$ nitric oxide; $\mathrm{PI} 3 \mathrm{~K}=$ phosphoinositide 3-kinase; $\mathrm{mTOR}=$ mammalian target of rapamycin; S6K1/2 = S6 kinase 1; MEK = methyl ethyl ketone; ERK = extracellular signal-regulated kinases; $\mathrm{BAD}=\mathrm{Bcl}$-2-associated death promoter; $\mathrm{AMPK}=\mathrm{AMP}$ activated protein kinase. explaining exercise-related reductions in the depressive symptoms of MDD subjects and overall improvements in mental health [5]. Furthermore, evidence from an animal study showed that a combination of regular exercise and pharmacological treatment contributed to a greater observed increase in the expression of BDNF mRNA in the dentate gyrus than either intervention alone [112].

The production of BDNF, IGF-1 and VEGF is important not only for neurogenesis but also for the maintenance of neurons [113] and the prevention of PD. These neurotrophic factors and others can be induced by muscle contraction and can cross the blood-brain barrier. Therefore, BDNF, IGF-1 and VEGF act directly on brain structures. Moreover, ROS produced by exercise requires greater antioxidant activity, which improves signaling related to deoxyribonucleic acid (DNA) repair and induces 
the production of antioxidant enzymes [114]. Altogether, aerobic exercise induces PGC- $1 \alpha$, a factor that stimulates mitochondrial biogenesis [115].

In conclusion, there are many neurobiological hypotheses that account for the variety of observed responses to exercise. In general, physical exercise appears to stimulate the synthesis and release of neuromodulators that are important for the maintenance of behavior and cognition beyond coping with stress, and exercise stimulates the formation of new neurons and blood vessels, thereby promoting mental health (fig. 3 ).

\section{Conclusion}

We conclude that regular physical training can reduce the severity of several symptoms that are related to various mental disorders such as depression, $A D$ and PD. There are many neurobiological hypotheses that may explain the wide variety of observed responses to exercise. Acute exercise appears to improve mood by ac- tivating specific cortical areas and by inducing the release of neurotransmitters and trophic factors that contribute to adherence to a program of regular physical activity. Chronic physical exercise appears to induce both neurogenesis and angiogenesis, which are important for improving behavioral and cognitive function and for improving the health of patients with mental disorders. Moreover, as the studies of athletes that were discussed in this article have shown, physical exercise can modulate mental health in both constructive and destructive ways.

\section{Acknowledgment}

This research was supported in part by the Conselho Nacional de Desenvolvimento Científico e Tecnológico (CNPq).

\section{Disclosure Statement}

The authors have no conflicts of interest to disclose.

\section{References}

1 Krouse R, Wickwire GC, Burge WE: Warmup period in physical exercise in relation to brain potential. Fed Proc 1946;5:57.

2 Vrba R: Significance of glutamic acid in metabolic processes in the rat brain during physical exercise. Nature 1955;176:1258-1261.

3 Pires FD: Thomas Kuhn's 'structure of scientific revolutions' applied to exercise science paradigm shifts: example including the central governor model. Br J Sports Med 2012 (Epub ahead of print).

4 Noakes TD: Is it time to retire the A.V. Hill model? A rebuttal to the article by Professor Roy Shephard. Sports Med 2011;41:263277.

5 Deslandes A, Moraes H, Ferreira C, Veiga H, Silveira H, Mouta R, Pompeu FA, Coutinho ES, Laks J: Exercise and mental health: many reasons to move. Neuropsychobiology 2009; 59:191-198.

6 Williams DM: Exercise, affect, and adherence: an integrated model and a case for selfpaced exercise. J Sport Exerc Psychol 2008;30: 471-496.

7 Blay SL, Andreoli SB, Fillenbaum GG, Gastal FL: Depression morbidity in later life: prevalence and correlates in a developing country. Am J Geriatr Psychiatry 2007;15:790-799.

8 Brookmeyer R, Johnson E, Ziegler-Graham K, Arrighi HM: Forecasting the global burden of Alzheimer's disease. Alzheimers Dement 2007;3:186-191.
9 Ahlskog JE: Does vigorous exercise have a neuroprotective effect in Parkinson disease? Neurology 2011;77:288-294.

10 Dishman RK, Berthoud HR, Booth FW, Cotman CW, Edgerton VR, Fleshner MR, Gandevia SC, Gomez-Pinilla F, Greenwood $\mathrm{BN}$, Hillman $\mathrm{CH}$, Kramer AF, Levin BE, Moran TH, Russo-Neustadt AA, Salamone JD, Van Hoomissen JD, Wade CE, York DA, Zigmond MJ: Neurobiology of exercise. Obesity (Silver Spring) 2006;14:345-356.

11 Garber CE, Blissmer B, Deschenes MR, Franklin BA, Lamonte MJ, Lee IM, Nieman DC, Swain DP: American College of Sports Medicine position stand. Quantity and quality of exercise for developing and maintaining cardiorespiratory, musculoskeletal, and neuromotor fitness in apparently healthy adults: guidance for prescribing exercise. Med Sci Sports Exerc 2011;43:1334-1359.

12 Guthold R, Ono T, Strong KL, Chatterji S, Morabia A: Worldwide variability in physical inactivity a 51-country survey. Am J Prev Med 2008;34:486-494.

13 Williams DM, Dunsiger S, Ciccolo JT, Lewis BA, Albrecht AE, Marcus BH: Acute affective response to a moderate-intensity exercise stimulus predicts physical activity participation 6 and 12 months later. Psychol Sport Exerc 2008;9:231-245.

14 Armstrong LE, VanHeest JL: The unknown mechanism of the overtraining syndrome: clues from depression and psychoneuroimmunology. Sports Med 2002;32:185-209.

15 Schaal K, Tafflet M, Nassif H, Thibault V, Pichard C, Alcotte M, Guillet T, El Helou N, Berthelot G, Simon S, Toussaint JF: Psychological balance in high level athletes: genderbased differences and sport-specific patterns. PLoS One 2011;6:e19007.

16 Reardon CL, Factor RM: Sport psychiatry: a systematic review of diagnosis and medical treatment of mental illness in athletes. Sports Med 2010;40:961-980.

17 Loucks AB: Refutation of 'the myth of the female athlete triad'. Br J Sports Med 2007;41: 55-58.

18 WHO: Ten statistical highlights in global public health. World Health Statistics 2007. Geneva, WHO, 2007.

19 Lopez-Munoz F, Alamo C: Monoaminergic neurotransmission: the history of the discovery of antidepressants from 1950s until today. Curr Pharm Des 2009;15:1563-1586.

20 Nestler EJ, Barrot M, DiLeone RJ, Eisch AJ, Gold SJ, Monteggia LM: Neurobiology of depression. Neuron 2002;34:13-25.

21 Blumenthal JA, Babyak MA, Doraiswamy PM, Watkins L, Hoffman BM, Barbour KA, Herman S, Craighead WE, Brosse AL, Waugh R, Hinderliter A, Sherwood A: Exercise and pharmacotherapy in the treatment of major depressive disorder. Psychosom Med 2007; 69:587-596. 
22 Dunn AL, Trivedi MH, Kampert JB, Clark CG, Chambliss HO: Exercise treatment for depression: efficacy and dose response. Am J Prev Med 2005;28:1-8.

23 Singh NA, Stavrinos TM, Scarbek Y, Galambos G, Liber C, Fiatarone Singh MA: A randomized controlled trial of high versus low intensity weight training versus general practitioner care for clinical depression in older adults. J Gerontol A Biol Sci Med Sci 2005;60:768-776.

24 Deslandes AC, Moraes H, Alves H, Pompeu FA, Silveira H, Mouta R, Arcoverde C, Ribeiro P, Cagy M, Piedade RA, Laks J, Coutinho ES: Effect of aerobic training on EEG $\alpha$ asymmetry and depressive symptoms in the elderly: a 1-year follow-up study. Braz J Med Biol Res 2010;43:585-592.

25 Silveira H, Moraes H, Oliveira N, Coutinho ES, Laks J, Deslandes A: Physical exercise and clinically depressed patients: a systematic review and meta-analysis. Neuropsychobiology 2013;67:61-68.

26 Krogh J, Nordentoft M, Sterne JA, Lawlor DA: The effect of exercise in clinically depressed adults: systematic review and metaanalysis of randomized controlled trials. J Clin Psychiatry 2011;72:529-538.

27 Ferri CP, Prince M, Brayne C, Brodaty H, Fratiglioni L, Ganguli M, Hall K, Hasegawa K, Hendrie H, Huang Y, Jorm A, Mathers C, Menezes PR, Rimmer E, Scazufca M: Global prevalence of dementia: a Delphi consensus study. Lancet 2005;366:2112-2117.

28 Gatz M: Educating the brain to avoid dementia: can mental exercise prevent Alzheimer disease? PLoS Med 2005;2:e7.

29 Valenzuela M, Sachdev P: Can cognitive exercise prevent the onset of dementia? Systematic review of randomized clinical trials with longitudinal follow-up. Am J Geriatr Psychiatry 2009;17:179-187.

30 Woods B, Aguirre E, Spector AE, Orrell M: Cognitive stimulation to improve cognitive functioning in people with dementia. Cochrane Database Syst Rev 2012;2:CD005562.

31 Hamer M, Chida Y: Physical activity and risk of neurodegenerative disease: a systematic review of prospective evidence. Psychol Med 2009;39:3-11.

32 Heyn P, Abreu BC, Ottenbacher KJ: The effects of exercise training on elderly persons with cognitive impairment and dementia: a meta-analysis. Arch Phys Med Rehabil 2004; 85:1694-1704.

33 Cooper C, Mukadam N, Katona C, Lyketsos CG, Blazer D, Ames D, Rabins P, Brodaty H, de Mendonca Lima C, Livingston G: Systematic review of the effectiveness of pharmacologic interventions to improve quality of life and well-being in people with dementia. Am J Geriatr Psychiatry 2013;21:173-183.

34 Forbes D, Forbes S, Morgan DG, Markle-Reid M, Wood J, Culum I: Physical activity programs for persons with dementia. Cochrane Database Syst Rev 2008:CD006489.

35 Hauer K, Schwenk M, Zieschang T, Essig M, Becker C, Oster P: Physical training improves motor performance in people with dementia: a randomized controlled trial. J Am Geriatr Soc 2012;60:8-15.

36 Stranahan AM, Martin B, Maudsley S: Antiinflammatory effects of physical activity in relationship to improved cognitive status in humans and mouse models of Alzheimer's disease. Curr Alzheimer Res 2012;9:86-92.

37 Muangpaisan W, Hori H, Brayne C: Systematic review of the prevalence and incidence of Parkinson's disease in Asia. J Epidemiol 2009; 19:281-293.

38 Wider C, Wszolek ZK: Etiology and pathophysiology of frontotemporal dementia, Parkinson disease and Alzheimer disease: lessons from genetic studies. Neurodegener Dis 2008; 5:122-125.

39 Das SK, Misra AK, Ray BK, Hazra A, Ghosal MK, Chaudhuri A, Roy T, Banerjee TK, Raut DK: Epidemiology of Parkinson disease in the city of Kolkata, India: a community-based study. Neurology 2010;75:1362-1369.

40 Ashburn A, Fazakarley L, Ballinger C, Pickering R, McLellan LD, Fitton C: A randomised controlled trial of a home based exercise programme to reduce the risk of falling among people with Parkinson's disease. J Neurol Neurosurg Psychiatry 2007;78:678-684.

41 Xu Q, Park Y, Huang X, Hollenbeck A, Blair A, Schatzkin A, Chen H: Physical activities and future risk of Parkinson disease. Neurology 2010;75:341-348.

42 Gallo P, Garber E: Parkinson's disease: a comprehensive approach to exercise prescription for the health fitness professional. ACSMs Health Fitness J 2011;15:8-17.

43 Katzel LI, Sorkin JD, Macko RF, Smith B, Ivey FM, Shulman LM: Repeatability of aerobic capacity measurements in Parkinson disease. Med Sci Sports Exerc 2011;43:2381-2387.

44 Hirayama MS, Gobbi S, Gobbi LT, Stella F: Quality of life in relation to disease severity in Brazilian Parkinson's patients as measured using the WHOQOL-BREF. Arch Gerontol Geriatr 2008;46:147-160.

45 Bloomer RJ, Schilling BK, Karlage RE, Ledoux MS, Pfeiffer RF, Callegari J: Effect of resistance training on blood oxidative stress in Parkinson disease. Med Sci Sports Exerc 2008; 40:1385-1389.

46 Hirsch MA, Toole T, Maitland CG, Rider RA: The effects of balance training and high-intensity resistance training on persons with idiopathic Parkinson's disease. Arch Phys Med Rehabil 2003;84:1109-1117.

47 Berchtold NC, Chinn G, Chou M, Kesslak JP, Cotman CW: Exercise primes a molecular memory for brain-derived neurotrophic factor protein induction in the rat hippocampus. Neuroscience 2005;133:853-861.

48 Sutoo D, Akiyama K: Regulation of brain function by exercise. Neurobiol Dis 2003;13: $1-14$.

49 Gallo P, Garber EC: Parkinson's disease: a comprehensive approach to exercise prescription for the health fitness professional. ACSMs Health Fitness J 2011;15:8-17.
50 Ekkekakis P, Petruzzello SJ: Acute aerobic exercise and affect: current status, problems and prospects regarding dose-response. Sports Med 1999;28:337-374.

51 Caiozzo VJ, Davis JA, Ellis JF, Azus JL, Vandagriff R, Prietto CA, McMaster WC: A comparison of gas exchange indices used to detect the anaerobic threshold. J Appl Physiol 1982;53:1184-1189.

52 Ekkekakis P: Pleasure and displeasure from the body: perspectives from exercise. Cogn Emot 2003;17:213-239.

53 Ekkekakis P, Hall EE, Petruzzello SJ: The relationship between exercise intensity and affective responses demystified: to crack the 40 -year-old nut, replace the 40-year-old nutcracker! Ann Behav Med 2008;35:136-149.

54 Reed J, Ones DS: The effect of acute aerobic exercise on positive activated affect: a metaanalysis. Psychol Sport Exerc 2006;7:477514.

55 Bartlett JD, Close GL, MacLaren DP, Gregson W, Drust B, Morton JP: High-intensity interval running is perceived to be more enjoyable than moderate-intensity continuous exercise: implications for exercise adherence. J Sports Sci 2011;29:547-553.

56 Ekkekakis P: Let them roam free? Physiologi$\mathrm{cal}$ and psychological evidence for the potential of self-selected exercise intensity in public health. Sports Med 2009;39:857-888.

57 Larsen RJ, Diener E: Promises and problems with the circumplex model of emotion; in Clark MS (ed): Review of Personality and Social Psychology. Newbury Park/CA, Sage, 1992, vol 13, pp 25-59.

58 Werneck FZ, Filho MGB, Ribeiro LCS: Efeitos do exercício sobre os estados de humor: Uma revisão. Rev Bras Psicol Esporte Exerc 2006;0: 22-54.

59 Bartholomew JB, Moore J, Todd J, Todd J, Elrod CC: Psychological states following resistant exercise of different workloads. J Appl Sport Psychol 2001;13:399-410.

60 Bibeau WS, Moore JB, Mitchell NG, VargasTonsing T, Bartholomew JB: Effects of acute resistance training of different intensities and rest periods on anxiety and affect. J Strength Cond Res 2010;24:2184-2191.

61 Werneck FZ, Filho MGB, Ribeiro LS: Efeito agudo do tipo e da intensidade do exercício sobre os estados de humor. Rev Bras Ativid Fís Saúde 2010;15:211-217.

62 Bellezza PA, Hall EE, Miller PC, Bixby WR: The influence of exercise order on blood lactate, perceptual, and affective responses. J Strength Cond Res 2009;23:203-208.

63 Lazarus RS: How emotions influence performance in competitive sports. Sport Psychol 2000;14:229-252.

64 Broshek DK, Freeman JR: Psychiatric and neuropsychological issues in sport medicine. Clin Sports Med 2005;24:663-679, x.

65 Sciolino NR, Holmes PV: Exercise offers anxiolytic potential: a role for stress and brain noradrenergic-galaninergic mechanisms. Neurosci Biobehav Rev 2012;36:1965-1984. 
66 Nybo L, Secher NH: Cerebral perturbations provoked by prolonged exercise. Prog Neurobiol 2004;72:223-261.

67 Borg G: Borg's Perceived Exertion and Pain Scales. Champaign/IL, Human Kinetics, 1998.

68 Nybo L, Secher NH, Nielsen B: Inadequate heat release from the human brain during prolonged exercise with hyperthermia. J Physiol 2002;545:697-704.

69 Nybo L: Brain temperature and exercise performance. Exp Physiol 2012;97:333-339.

70 Rasmussen P, Stie H, Nybo L, Nielsen B: Heat induced fatigue and changes of the EEG is not related to reduced perfusion of the brain during prolonged exercise in humans. J Therm Biol 2004;29:731-737.

71 Roelands B, Meeusen R: Alterations in central fatigue by pharmacological manipulations of neurotransmitters in normal and high ambient temperature. Sports Med 2010;40:229-246.

72 Pennes HH: Analysis of tissue and arterial blood temperatures in the resting human forearm. J Appl Physiol 1948;1:93-122.

73 Van Lieshout JJ, Wieling W, Karemaker JM, Secher NH: Syncope, cerebral perfusion, and oxygenation. J Appl Physiol 2003;94:833-848.

74 Nielsen B, Nybo L: Cerebral changes during exercise in the heat. Sports Med 2003;33:1-11.

75 Nybo L, Nielsen B: Hyperthermia and central fatigue during prolonged exercise in humans. J Appl Physiol 2001;91:1055-1060.

76 Gonzalez-Alonso J, Teller C, Andersen SL, Jensen FB, Hyldig T, Nielsen B: Influence of body temperature on the development of fatigue during prolonged exercise in the heat. J Appl Physiol 1999;86:1032-1039.

77 Walters TJ, Ryan KL, Tate LM, Mason PA: Exercise in the heat is limited by a critical internal temperature. J Appl Physiol 2000;89: 799-806.

78 Girard O, Bishop DJ, Racinais S: Hot conditions improve power output during repeated cycling sprints without modifying neuromuscular fatigue characteristics. Eur J Appl Physiol 2013;113:359-369.

79 Newsholme EA, Acworth I, Blomstrand E: Amino acids, brain neurotransmitters and a function link between muscle and brain that is important in sustained exercise; in Benzi G (ed) Advances in Myochemistry. London, Libbey, 1987.

80 Meeusen R, De Meirleir K: Exercise and brain neurotransmission. Sports Med 1995;20:160188.

81 Pires FO, Lima-Silva AE, Bertuzzi R, Casarini DH, Kiss MA, Lambert MI, Noakes TD: The influence of peripheral afferent signals on the rating of perceived exertion and time to exhaustion during exercise at different intensities. Psychophysiology 2011;48:1284-1290.

82 St Clair Gibson A, Baden DA, Lambert MI, Lambert EV, Harley YX, Hampson D, Russell VA, Noakes TD: The conscious perception of the sensation of fatigue. Sports Med 2003;33: 167-176.

83 Hampson DB, St Clair Gibson A, Lambert MI, Noakes TD: The influence of sensory cues on the perception of exertion during exercise and central regulation of exercise performance. Sports Med 2001;31:935-952.

84 Felipo V, Butterworth RF: Neurobiology of ammonia. Prog Neurobiol 2002;67:259-279.

85 Dalsgaard MK, Nybo L, Cai Y, Secher NH: Cerebral metabolism is influenced by muscle ischaemia during exercise in humans. Exp Physiol 2003;88:297-302.

86 Kreher JB, Schwartz JB: Overtraining syndrome: a practical guide. Sports Health 2012; 4:128-138.

87 Kellmann M: Preventing overtraining in athletes in high-intensity sports and stress/ recovery monitoring. Scand J Med Sci Sports 2010;20(suppl 2):95-102.

88 Robazza C, Pellizzari M, Bertollo M, Hanin YL: Functional impact of emotions on athletic performance: comparing the IZOF model and the directional perception approach. J Sports Sci 2008;26:1033-1047.

89 Hanin YL: Individual Zones of Optimal Functioning (IZOF) Model: Na Idiographic Approach to Performance Anxiety. Longmeadow/MA, Movement Publications, 2007.

90 Robazza C, Pellizzari M, Hanin Y: Emotion self-regulation and athletic performance: an application of the IZOF model. Psychol Sport Exerci 2004;5:379-404.

91 Noakes TD, Lambert MI, Gleeson M: Heart rate monitoring and exercise: challenges for the future. J Sports Sci 1998;16(suppl):S105S106.

92 Noakes TD: Physiological models to understand exercise fatigue and the adaptations that predict or enhance athletic performance. Scand J Med Sci Sports 2000;10:123145.

93 Weir JP, Beck TW, Cramer JT, Housh TJ: Is fatigue all in your head? A critical review of the central governor model. Br J Sports Med 2006; $40: 573-586$.

94 Marcora SM: Do we really need a central governor to explain brain regulation of exercise performance? Eur J Appl Physiol 2008; 104:929-931.

95 Shephard RJ: Is it time to retire the 'central governor'? Sports Med 2009;39:709-721.

96 Sarbadhikari SN, Saha AK: Moderate exercise and chronic stress produce counteractive effects on different areas of the brain by acting through various neurotransmitter receptor subtypes: a hypothesis. Theor Biol Med Model 2006;3:33.

97 Dietrich A, McDaniel WF: Endocannabinoids and exercise. Br J Sports Med 2004;38: 536-541.

98 Duman RS: Neurotrophic factors and regulation of mood: role of exercise, diet and metabolism. Neurobiol Aging 2005;26(suppl 1): 88-93.

99 Walf AA, Paris JJ, Rhodes ME, Simpkins JW, Frye CA: Divergent mechanisms for trophic actions of estrogens in the brain and peripheral tissues. Brain Res 2011;1379:119-136.

100 Strohle A, Feller C, Strasburger CJ, Heinz A, Dimeo F: Anxiety modulation by the heart?
Aerobic exercise and atrial natriuretic peptide. Psychoneuroendocrinology 2006;31: 1127-1130.

101 Van Praag H, Kempermann G, Gage FH: Running increases cell proliferation and neurogenesis in the adult mouse dentate gyrus. Nat Neurosci 1999;2:266-270.

102 Van Praag H: Exercise and the brain: something to chew on. Trends Neurosci 2009;32 283-290.

103 Pereira AC, Huddleston DE, Brickman AM, Sosunov AA, Hen R, McKhann GM, Sloan R, Gage FH, Brown TR, Small SA: An in vivo correlate of exercise-induced neurogenesis in the adult dentate gyrus. Proc Natl Acad Sci USA 2007;104:56385643.

104 Stranahan AM, Lee K, Mattson MP: Central mechanisms of HPA axis regulation by voluntary exercise. Neuromolecular Med 2008; 10:118-127.

105 Papacosta E, Nassis GP: Saliva as a tool for monitoring steroid, peptide and immune markers in sport and exercise science. J Sci Med Sport 2011;14:424-434.

106 Lightman SL: The neuroendocrinology of stress: a never-ending story. J Neuroendocrinol 2008;20:880-884.

107 Walsh NP, Gleeson M, Shephard RJ, Woods JA, Bishop NC, Fleshner M, Green C, Pedersen BK, Hoffman-Goetz L, Rogers CJ, Northoff H, Abbasi A, Simon P: Position statement. Part 1: Immune function and exercise. Exerc Immunol Rev 2011;17:6-63.

108 Laugero KD: A new perspective on glucocorticoid feedback: relation to stress, carbohydrate feeding and feeling better. J Neuroendocrinol 2001;13:827-835.

109 Radak Z, Chung HY, Goto S: Systemic adaptation to oxidative challenge induced by regular exercise. Free Radic Biol Med 2008;44: 153-159.

110 Powers SK, Talbert EE, Adhihetty PJ: Reactive oxygen and nitrogen species as intracellular signals in skeletal muscle. J Physiol 2011;589:2129-2138.

111 Simpson RJ, Guy K: Coupling aging immunity with a sedentary lifestyle: has the damage already been done? A mini-review. Gerontology 2010;56:449-458.

112 Russo-Neustadt A, Beard RC, Cotman CW: Exercise, antidepressant medications, and enhanced brain-derived neurotrophic factor expression. Neuropsychopharmacology 1999;21:679-682.

113 Cotman CW, Berchtold NC, Christie LA Exercise builds brain health: key roles of growth factor cascades and inflammation. Trends Neurosci 2007;30:464-472.

114 Radak Z, Chung HY, Koltai E, Taylor AW, Goto S: Exercise, oxidative stress and hormesis. Ageing Res Rev 2008;7:34-42.

115 Marques-Aleixo I, Oliveira PJ, Moreira PI, Magalhaes J, Ascensao A: Physical exercise as a possible strategy for brain protection: evidence from mitochondrial-mediated mechanisms. Prog Neurobiol 2012;99:149-162. 